Historic, Archive Document

Do not assume content reflects current scientific knowledge, policies, or practices. 

USDA
United States Department of Agriculture
Animal and Plant Health Inspection Service

Program Aid No. 1710

Plant Protection and Quarantine:

Detecting Plant Pests and Weeds Through a National Survey Program 
-ome exotic plant pests leave immediate evidence - of their presence. Signs of disease, crop damage, or weed growth appear almost instantly. Other foreign pests, however, can go undetected for months or even years in the absence of proper surveillance. Without early detection, these insidious pests can become established in the United States and permanently damage agriculture and natural resources.

The U.S. Department of Agriculture's (USDA) Cooperative Agricultural Pest Survey (CAPS) strives to keep this from happening. Managed by USDA's Animal and Plant Health Inspection Service's (APHIS) Plant Protection and Quarantine (PPQ) program, CAPS reports finds and movements of damaging foreign organisms-exotic plant pests, diseases, and weeds - throughout the United States. CAPS is a critical tool in determining the extent and nature of a pest infestation.

The program has been instrumental in surveying for pests, including certain wood-boring beetles, that do not exist in the United States but have been intercepted at U.S. ports of entry. These pests potentially affect urban and natural areas and the Nation's lumber industry. This proactive work helps ensure that if these pests are found, they are detected

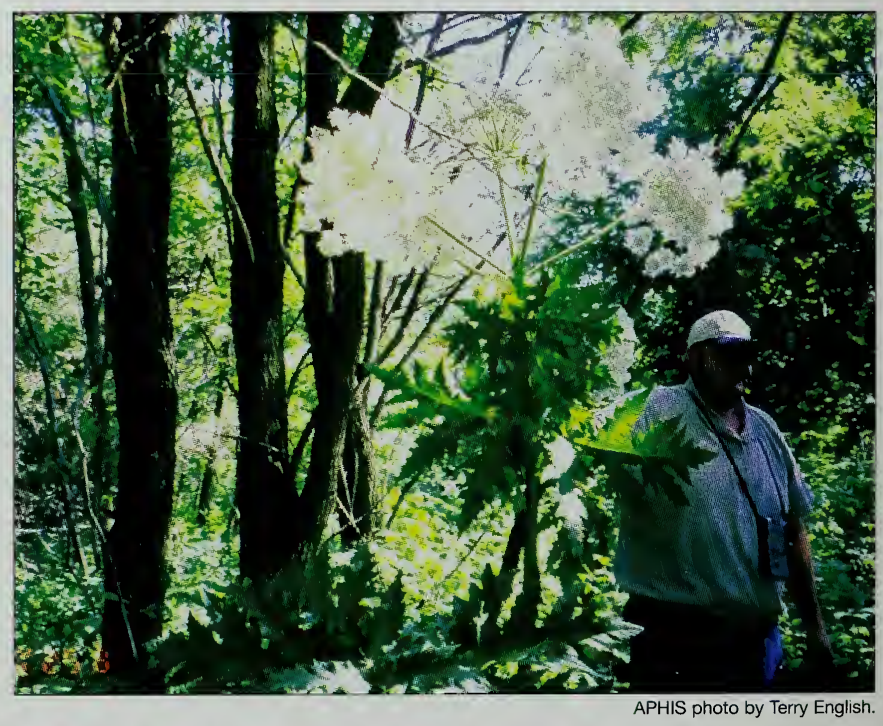

CAPS surveys for invasive plants declared as Federal noxious weeds. Giant hogweed (Heracleum mantegazzianum) is especially onerous because the sap that oozes from its branches can cause large, painful blisters. 


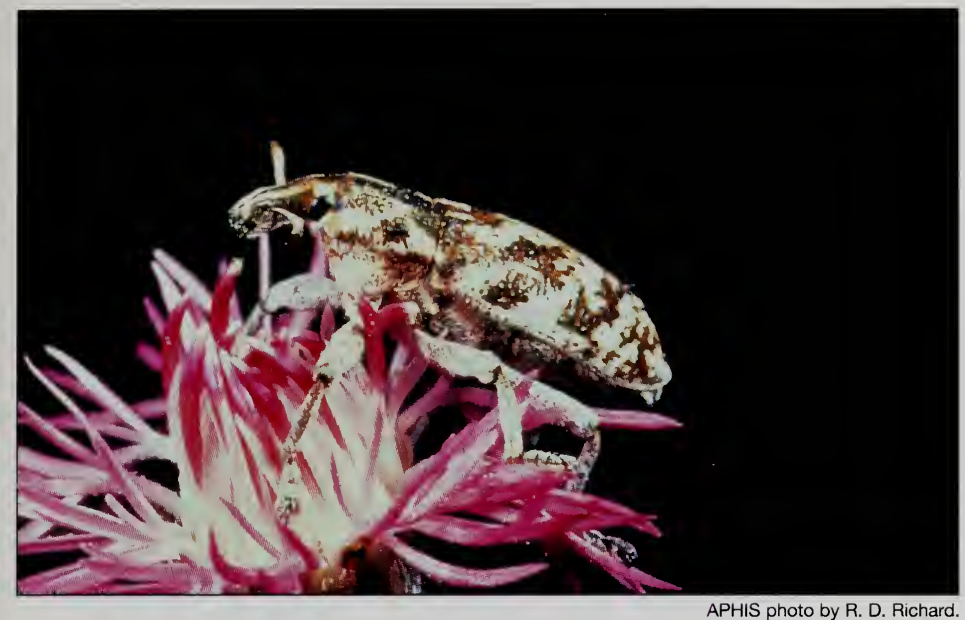

The knapweed root weevil (Cyphocieonus achates) was first released as a biocontrol agent in 1987 as part of a program to help control spotted and diffuse knapweeds in the Western United States. CAPS surveys annually for the weevil in order to determine its success in adapting to the region and dispersing to new areas to control knapweed infestations.

quickly before they can become established here. Early detection saves millions of dollars in control and eradication costs, protects our natural resources, and prevents the economic disruption of agricultural industries.

The National Agricultural Pest Information System (NAPIS) serves as the filing cabinet for all of the information that is collected through CAPS. The database maintains information on the findings of every CAPS survey and makes the information easily accessible to the public.

In an increasingly global economy involving greater international trade than ever before, pests affecting agriculture and natural areas can have a significant impact on the marketability of U.S. agricultural commodities throughout the world. CAPS' detailed distribution maps help assure U.S. trading partners that specific production areas and States are free of plant pests that may be of concern, preserving critical markets for U.S. producers.

\section{Gathering Survey Data}

CAPS is a cooperative project that combines the skills and resources of PPQ with those of State agricultural organizations and universities. PPQ supports each survey project with national, regional, and local coordination, technical assistance, and funding. The survey work is primarily carried out by personnel from each State. 


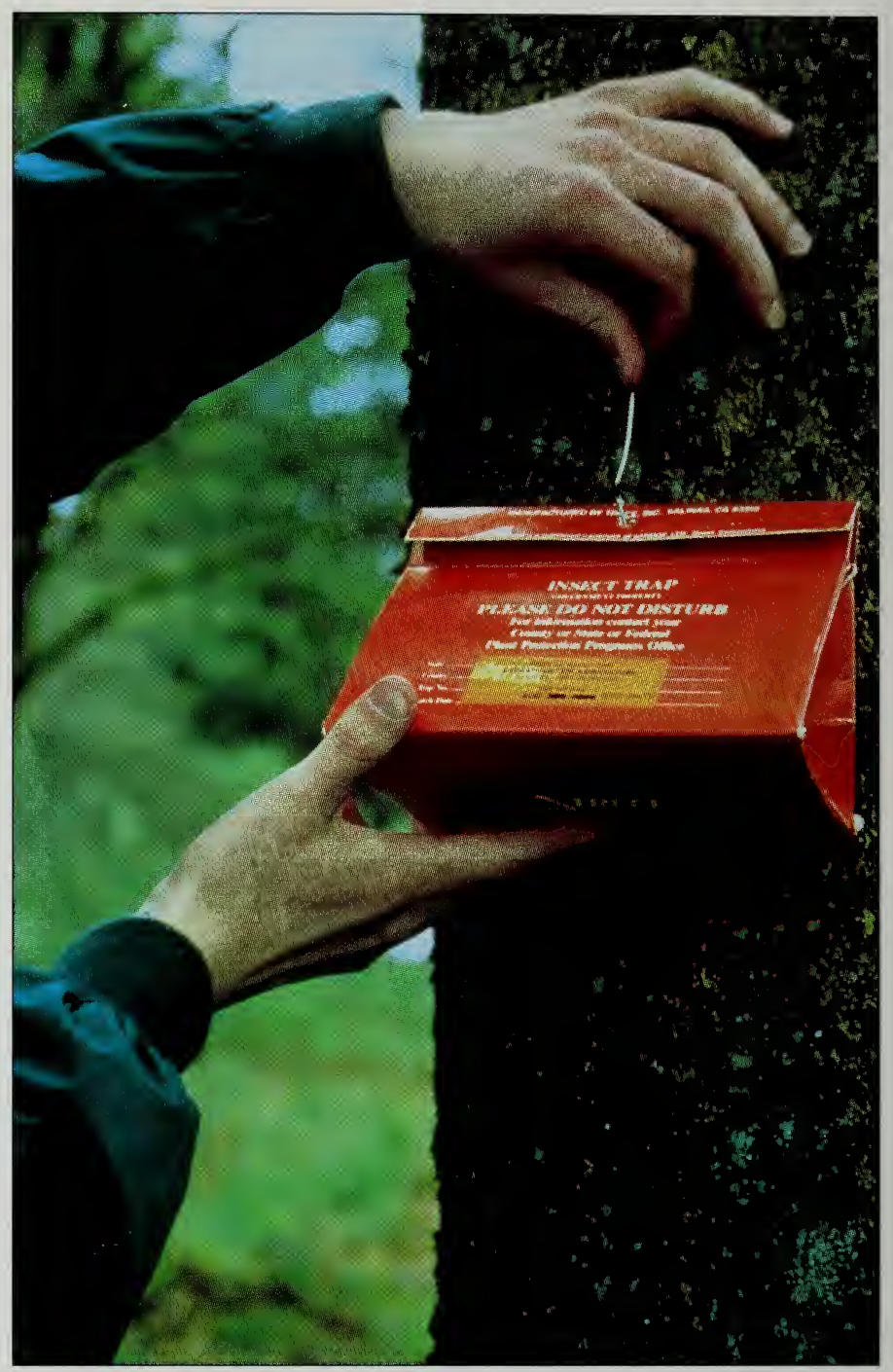

APHIS photo collection.

Delta traps like this one are hung throughout the United States to survey for the European gypsy moth, which feeds on the leaves of hardwood trees. The moths are attracted to a pheromone bait inside the trap, but once they get in, they are caught on a sticky substance and cannot escape.

Each year PPQ develops a list of potential survey targets and issues a call for survey proposals. This allows each State to understand PPQ's priorities for the upcoming year and complements State surveillance and detection needs. PPQ then works with national, regional, and State committees to determine what survey data will be collected and how it will be managed. 
In addition, CAPS tracks more than 4,000 pests nationwide. In the Northeast, the spread of the European gypsy moth (Lymantria dispar) is a concern, and this pest continues to move westward. From the South, the spread of the red imported fire ant (Solenopsis invicta) to new areas is being closely monitored. CAPS also tracks the distribution of Federal noxious weeds, such as giant salvinia (Salvinia molesta) and tropical soda apple (Solanum viarum), and the distribution of biological control organisms that have been strategically released to feed on or otherwise destroy the weeds.

While APHIS has been tracking the movement of some pests and diseases for years, new exotic threats are added to the list each year. Since the mid-1990s, CAPS has been surveying for Karnal bunt, a fungal disease of wheat. More recently, CAPS has coordinated and funded national surveys to track plum pox, a virus that affects peaches, nectarines, and plums.

The CAPS survey data collected each year are entered into the NAPIS database and used to determine pest distribution and population levels, the life-stages of specific target insects, first occurrences, and other pest-related phenomena of local interest. When looked at in their entirety, these data are unparalleled in tracking the spread of exotic pests and measuring their success in adapting to their new environments.

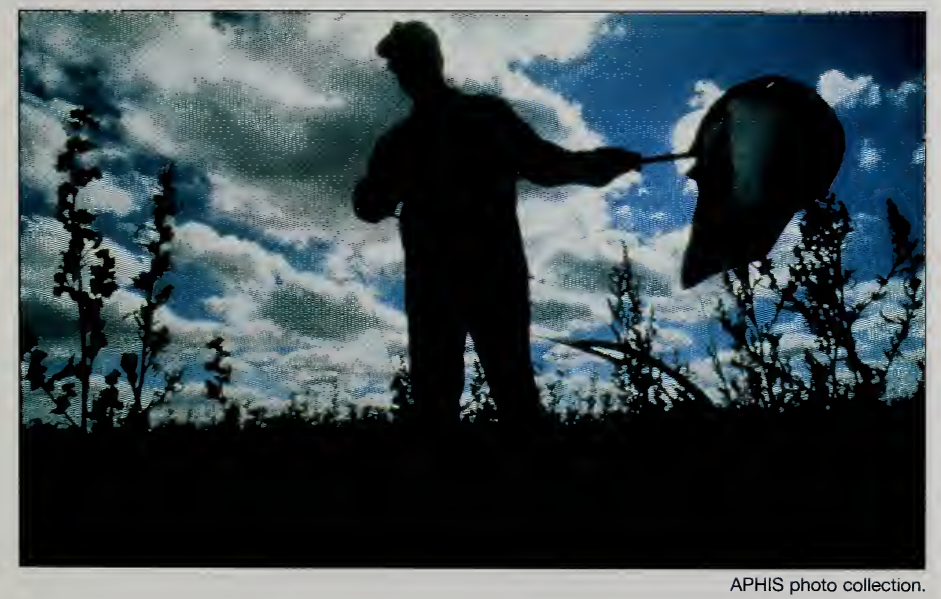

Surveyors use large nets like this one to sweep rangeland vegetation for invasive pests like Mormon crickets (Anabrus simplex) and biological control agents that are tracked annually. 


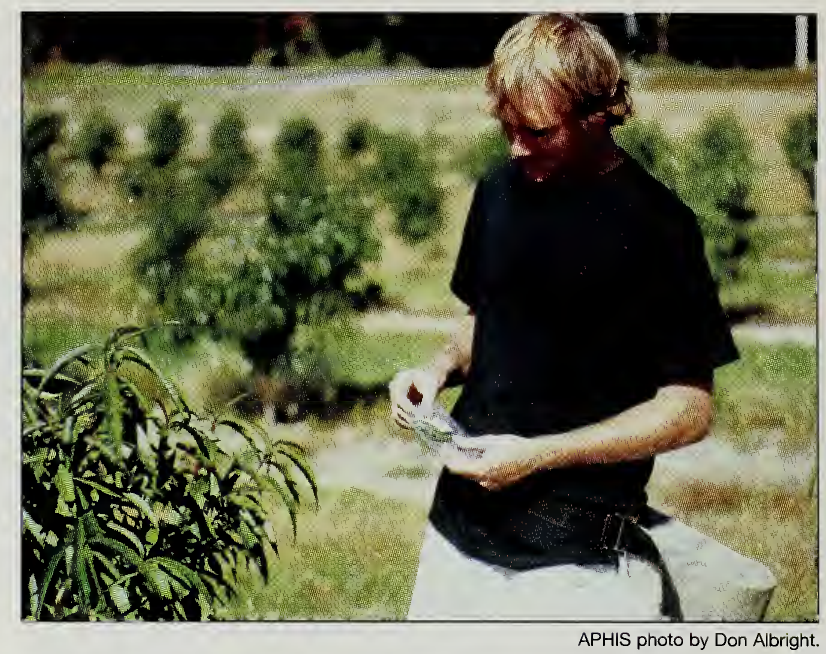

Thousands of stone-fruit trees must be sampled each year for plum pox, also known as sharka. Every orchard sample taken is labeled so that any positive test results can be traced back to the location where the trees are infected.

\section{Tools for Tracking Pests}

CAPS cooperators use many different tools and techniques to track the movement of exotic plant pests, diseases, and weeds. Much of the work is done out in the field, where all sampling takes place. Surveyors hang red traps containing bait from trees to attract gypsy moths and collect soil from fields to look for harmful nematodes that feed on more that 2,000 fruits and vegetables. Leaves from stone-fruit trees are painstakingly collected to test for the presence of plum pox, a disease that affects fruit production and is spread to other trees by aphids. In the West, new Federal noxious weed surveys are conducted, sometimes from the air. On the ground, biological control agents are captured using sweep nets to determine their success in dispersing to new areas.

The information gathered in the field is then sent to laboratories across the United States, where specialists identify pests caught in traps, plant pathologists analyze leaves collected from trees to determine if they are healthy or diseased, and botanists identify weed specimens. 


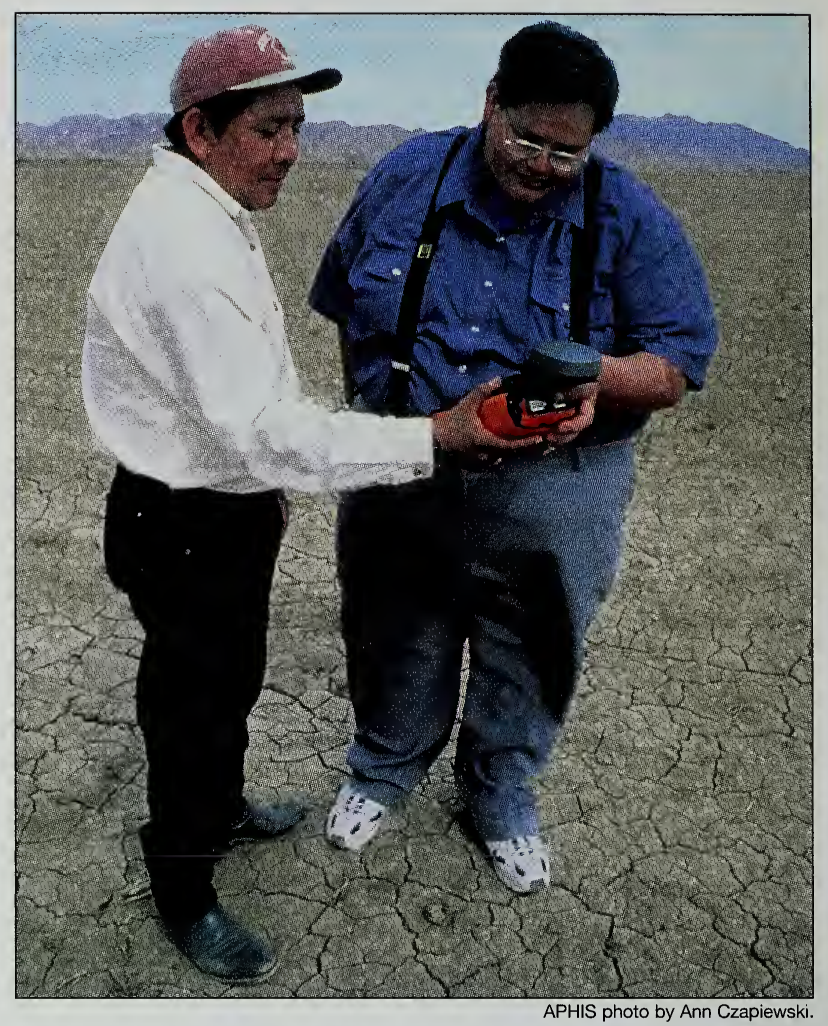

Hand-held GPS devices are used by most CAPS surveyors to determine the exact coordinates of every field that is sampled for exotic pests, diseases, and weeds. The data are then used to create survey maps detailing the distribution of each pest.

Each sample is marked so that once the laboratory work is complete, positive test results can be traced back to the location where the sample was originally taken. It does not matter whether the sample was taken from an isolated forest or a residential backyard: state-of-the-art technology enables surveyors to record each sample with the use of hand-held global positioning system (GPS) devices that generate longitude and latitude coordinates. The reporting of these critical data allows plant health experts to initiate control or eradication efforts quickly. The coordinates of the detection are also plotted onto a map that details the distribution of the pest within the United States. Every year, PPQ personnel create a similar map for every pest surveyed through CAPS and post the maps on the NAPIS Web site. 


\section{Reported distibution of cereal leaf beetle, Oulema melanopus, in the continental United States}

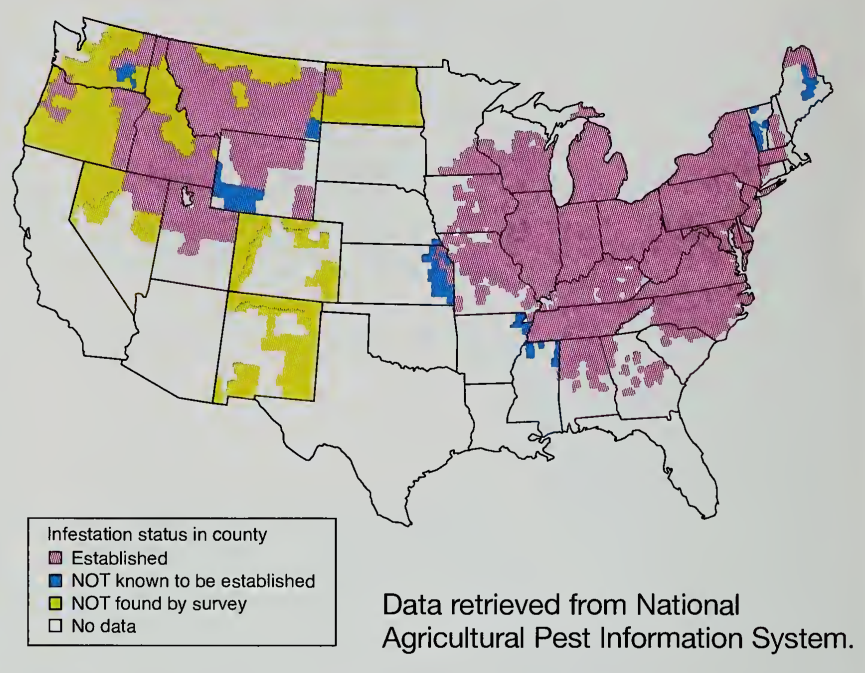

Adapted from the October 9, 2001, map of cereal leaf beetle on the NAPIS Web site, managed by Purdue University.

In the 1970s, the cereal leaf beetle spread to all parts of the Midwest and the Northeast. CAPS continues to survey for the beetle in areas where it already is established as well as in surrounding areas where the beetle has not yet been found.

United States field surveys were taken and where, if at all, a particular pest was detected. The NAPIS database also makes available survey maps from previous years. When looked at sequentially, these maps show the movement of a particular pest over time.

NAPIS is a key tool for foreign countries looking to import agricultural commodities from the United States. More than 75 countries access the site each month to view maps and other information to ensure that U.S. agricultural goods destined for their country are pest and disease free. In total, the site receives more than 60,000 hits a month.

PPQ frequently uses the NAPIS database to provide pertinent information to U.S. trading partners. For example, if a country wants to know the distribution of 10 pests of concern in the United States, that information can quickly be pulled from the NAPIS site. The database can also be useful if a trading partner wants to know which States or regions have been surveyed for a particular pest. 
In addition to the public Web site, which has substantial pest detection and mapping data, PPQ and other cooperators can also access CAPS' restricted site. This limited-access site provides a mom indonth lnok at the latest CAPS survey data.

\section{Looking to the Future}

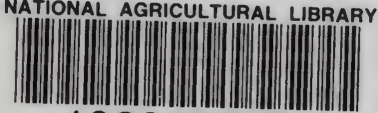

1022499771

As the United States continues to expand its export markets around the world and increase the variety of agricultural commodities it imports, CAPS will be at the forefront of shaping the rules and regulations for safeguarding U.S. agriculture and natural resources in the 21 st century. The national survey work meticulously gathered by PPQ and its cooperators is essential for understanding the scope of foreign pests in the United States today. CAPS is one of the most important tools to prevent an exotic pest from making a permanent home in the United States. In addition to surveying for pests that have already been detected, the CAPS program will continue to expand its work to search for pests that have not yet been found in the United States but are considered to be a potential threat. This advance work will put PPQ far ahead of the curve in its efforts to prevent the establishment of foreign plant pests, diseases, and weeds here in the United States.

The U.S. Department of Agriculture (USDA) prohibits discrimination in all its programs and activities on the basis of race, color, national origin, sex, religion, age, disability, political beliefs, sexual orientation, or marital or family status. (Not all prohibited bases apply to all programs.) Persons with disabilities who require alternative means for communication of program information (Braille, large print, audiotape, etc.) should contact USDA's TARGET Center at (202) 720-2600 (voice and TDD).

To file a complaint of discrimination, write USDA, Director, Office of Civil Rights, Room 326-W, Whitten Building, 1400 Independence Avenue, SW, Washington, DC 20250-9410 or call (202) 720-5964 (voice and TDD). USDA is an equal opportunity provider and employer. 
